\title{
Viajeros de la avanzada del capitalismo. La visión de Gaspard Théodore Mollien sobre la política de la Nueva Granada en la post - independencia*
}

\author{
Viviana Olave Quintero**
}

\section{Resumen}

La literatura de viajes de principios del siglo XIX dedicada a las nuevas repúblicas de Sudamérica se ocupó en gran parte de la descripción de los recursos naturales y humanos. Dentro de estas descripciones, es innegable que también examinaron la cuestión política de las antiguas posesiones españolas y el presente artículo de investigación se centra, previo paso por unas consideraciones generales, en el análisis que el controversial Gaspard Théodore Mollien, viajero francés, realizó sobre el estado político de la Nueva Granada en 1823.

\section{Palabras Claves}

Independencia, Literatura de Viajes, Política, Francia, Siglo XIX, Nueva Granada

\begin{abstract}
The literature of travelers dedicated to the new republics of South America at the beginning of the 19th Century was devoted, in large part, to the description of the natural and human resources. Among these descriptions, it is undeniable that the authors also examined the political issues of the ancient Spanish colonies. The present article is centered - with general considerations- to the analysis of the controversial Gaspar Theodore Mollien, a French traveler who engaged his writings on the political state of the Nueva Granada in 1823.
\end{abstract}

\section{Key words}

Independence, Travel Literature, Politics, France, 19th century, Nueva Granada.

\section{Introducción}

Los viajes han sido una constante a lo largo de la historia de la humanidad. El hombre siempre ha buscado nuevas experiencias que le han permitido entrar en contacto con otras culturas y, por supuesto, América y todos los territorios no se han librado de este hecho desde el siglo XVI. Es así como la tradición de viajes en Europa cobra un importante peso histórico que permite resaltar ciertas épocas y personajes como puntos claves del desarrollo de la cultura de viajes europea. En esta tradición, podemos destacar, en la Edad Media, a Marco Polo (1254-1324) y su experiencia con oriente; durante el Renacimiento, a Colón (1451-1506), con el

\footnotetext{
* Artículo tipo 2: de reflexión, según clasificación de Colciencias. Resultado de la Tesis de Grado presentada como requisito para obtener el título de Licenciada en Historia de Facultad de Humanidades de la Universidad del Valle, noviembre del 2009.

${ }^{* *}$ Licenciada en Historia de la Universidad del Valle. Integrante del grupo Nación-Cultura-Memoria adscrito al Departamento de Historia de la Universidad del Valle. Asistente de investigación del proyecto Catalogación de Libros Antiguos de la Biblioteca Mario Carvajal. E mail: viviola911@ hotmail.com
} 
descubrimiento de América y la descripción de lo que fueron las experiencias en un continente desconocido por los europeos y, por supuesto, en la llustración a Humboldt (1769-1859) y Mutis (1732-1808) como viajeros científicos que se trasladaron a América con el objetivo de medir y clasificar la naturaleza del Nuevo Continente. A esta tradición también pertenecen los viajeros de principios del siglo XIX, hombres y mujeres que arribaron a los puertos de Sudamérica, después de haberse proclamado la independencia, con el propósito de observar las posibilidades de inversión de capital, de extracción de materias primas y de creación de mercados para los productos europeos.

Los viajeros europeos que arribaron a América entre 1820 y 1830 fueron los viajeros de la avanzada del capitalismo, concepto utilizado por Carlos Sanhueza Cerda (2006) para describir a un grupo de viajeros europeos que se encargó de la clasificación de los recursos naturales y humanos del Nuevo Continente. La visión de este grupo estuvo estrechamente relacionada con las posibilidades económicas que las ex colonias representaban para sus lugares de origen: Francia, Inglaterra, Alemania, Suecia, etc.

En los inicios del siglo XIX, según Sanhueza Cerda (2006, p. 26), los relatos de viaje tuvieron un papel utilitario al convertir los lugares que visitaban en laboratorios científicos desde los cuales se podían comprobar teorías sobre la flora y la fauna, o definir zonas de posible explotación minera y agrícola y realizar descripciones de la población enfatizando en lo posible sobre el potencial de sus habitantes para convertirse en mercados económicos. En definitiva, el objetivo de estas descripciones, como lo expresa Ottmar Ette (1999, p. 65), era posibilitar que los tesoros de la naturaleza tropical en un futuro -no muy lejano- fueran explotados por las potencias europeas. A pesar de que lo económico fue determinante en los libros de viajes, hay que tener en cuenta que en ellos también hubo espacio para el examen del estado moral y político de la sociedad, que permitiría a los viajeros conocer el tipo de sociedad con la que su nación instauraría relaciones económicas y políticas.

Realmente, el examen del estado político que aparece en los libros de viajes ha sido poco estudiado por los historiadores, debido a que la mayor parte del contenido de los libros de viajes se encuentra dedicado a la ubicación y clasificación de los recursos naturales y humanos. Así, muchos de los comentarios sobre la política terminan desdibujándose en los datos sobre la demografía, la minería, la flora y la fauna del territorio. Esta es una de las razones por la que aquí nos ocuparemos del examen político que realizó el viajero francés Gaspard Théodore Mollien en su libro Viaje por la republica de Colombia en $1823^{1}$.

\footnotetext{
${ }^{1}$ Viaje por la república de Colombia en 1823 fue publicado en francés por la librería de Arthus Bertrand. Este ejemplar en su idioma original tuvo dos ediciones: la primera fue la de 1824 , con un mapa de la Gran Colombia y ocho ilustraciones; la segunda de 1825, con algunas correcciones de forma. El escrito original en francés, según Jorge Orlando Melo (2007), fue traducido en poco tiempo, entre 1825 y 1830, a varios idiomas: en 1825, inglés; en sueco hacia 1826; apareció en alemán e italiano en 1830. La versión en español fue más bien tardía, apareció en 1944 con la edición de la Biblioteca Popular de Cultura Colombiana. Definitivamente, el recorrido de Mollien se volvió más asequible con la edición que preparó la Presidencia de
} 
Mollien hizo parte de los viajeros de la avanzada del capitalismo, de ahí que dediquemos la primera parte del artículo a dos aspectos: 1) La transformación política y económica que acaeció a ambos lados del atlántico a finales del siglo XVIII y principios del siglo XIX e impulsó la llegada de europeos a América, y 2) La descripción de las características de este tipo de viajero.

La segunda parte se centrará en el caso de Gaspard Théodore Mollien y su crítica al sistema de gobierno y a Simón Bolívar, comentarios que el viajero francés se atrevió a sostener en un contexto donde las potencias europeas y las ex colonias españolas buscaban instaurar relaciones diplomáticas.

El caso de Mollien es muy peculiar, pues, como sostiene Jaime Jaramillo Uribe (2002, p. 16) entre los viajeros que llegaron a Colombia a principios del siglo XIX, este viajero francés fue quien "dejó un panorama más completo del estado y posibilidades de la nación en el campo económico", ya que no sólo se dedicó a la observación minuciosa, sino que también estudió algunos documentos oficiales que le proporcionaron información sobre las finanzas públicas, el comercio, la minería y, en general, sobre la riqueza agrícolas del país. Sin embargo, Viaje por la república de Colombia en 1823 impactó la opinión pública de la época no por sus comentarios sobre lo económico, sino por sus fuertes críticas sobre algunos aspectos políticos.

\section{Los viajeros de la avanzada del capitalismo. Los nuevos "conquistadores" de los recursos naturales de América.}

El siglo XIX fue, sin duda, un siglo de cambios no sólo en el territorio europeo sino también en América. Fueron precisamente estas transformaciones a ambos lados del Atlántico lo que impulsó y permitió el arribo al Nuevo Mundo de los viajeros de la avanzada del capitalismo. Podemos identificar tres hechos importantes que impulsaron el viaje de muchos europeos hacia América: la expansión comercial de las potencias europeas; la expansión de los medios de transporte; y, por supuesto, la independencia de los territorios americanos.

Respecto a la expansión comercial, desde el siglo XVIII eran evidentes las intenciones comerciales que las potencias europeas tenían sobre el continente americano, pues la Revolución Industrial y el impulso del capitalismo exigían nuevos mercados, lugares de extracción de materias primas y zonas para la inversión (Jaramillo, 2002, p. 7). América se convirtió desde este punto de vista en un lugar que posibilitaba todos estos procesos por la riqueza natural de su territorio. Sin embargo, este proceso de expansión no se pudo desarrollar plenamente en el siglo XVIII, pues el poder colonial español se convirtió en su mayor obstáculo. El viajero Carl August Gosselman (1799-1843), quien visitó Colombia entre 1824 y 1825, nos explica cómo durante la época colonial España trató por todos los medios de mantener aisladas a sus colonias del resto del

la república, la Comisión Preparatoria para el V Centenario del Descubrimiento de América, el Instituto Colombia de Cultura- Colcultura y la Biblioteca Nacional de Colombia, en 1992. 
mundo y este proceso implicó el cierre total de sus fronteras a cualquier posibilidad de visita extranjera:

El problema mayor [para España] estaba en conseguir aislar a las colonias del resto del mundo. Los esfuerzos que debían realizarse eran mayúsculos, ya que no se trataba exclusivamente de evitar el vencimiento de unas pocas plantas, sino de erradicar y destruir para las ciencias el avance de una parte del mundo. España pretendía detener la información impidiendo, incluso, que a los territorios conquistados tuvieran ingresos forasteros. El único que podía permitir la entrada a un extraño- léase no español, ni conquistador- era el gobierno. Los viajes solo eran autorizados en determinadas provincias, y que un criollo quisiera viajar al extranjero era punto menos que imposible (Gosselman, 1981, p. 296).

Así, las potencias europeas tuvieron que esperar hasta el siglo XIX, cuando las murallas del colonialismo se derrumbaron, para adentrarse al interior de América. Sólo después de 1810 los extranjeros tuvieron la posibilidad de pasearse por el territorio americano y llevar a cabo su proyecto de expansión comercial.

Dicha expansión se vio impulsada por el progreso de los medios de transporte generado por la Revolución Industrial, afirmación que comparten Jaime Jaramillo Uribe (2002, p. 7), Ángela María Pérez (2002, p. 99) y Carlos Sanhueza Cerda (2006, p. 46), pues los desplazamientos por el mundo no sólo de mercancías sino de personas se pudieron realizar, constantemente, en la medida que se contaba con medios de transportes más efectivos. La evolución de los medios de transporte también nos permite entender la masiva migración de viajeros hacia América, pues en los inicios del siglo XIX los desplazamientos hacia el Nuevo Mundo no implicaban las largas distancias, que se acortaron con el barco a vapor, ni los riesgos que tuvieron que afrontar los conquistadores en el siglo XVI.

Carlos Sanhueza (2006, pp. 46-47) considera que en los inicios del siglo XIX empezó un desarrollo importante de los medios de transporte. Retomando a Marjorie Morgan, dice que durante este siglo los viajeros tuvieron la posibilidad de disponer de varios vehículos, así como medios de transporte como los carruajes, que mejoraron considerablemente; y los canales y ríos que, aunque, ya hacía siglos servían de medio de transporte, se volvieron más efectivos con la introducción del barco a vapor. Del mismo modo, el viaje a ultramar tuvo importantes cambios que se vislumbraron en el aumento de la capacidad de transporte y la disminución del tiempo de los recorridos.

La expansión comercial y el desarrollo de los medios de transporte fueron procesos de suma importancia que crearon las condiciones para que un número considerable de viajeros migrara en los inicios del siglo XIX. Sin embargo, aunque estos procesos fueron importantes, el hecho histórico que tendrá mayor peso en el impulso de los viajes de europeos hacia América fue el proceso de independencia, que permitiría establecer relaciones comerciales y políticas más activas entre el Viejo y el Nuevo mundo (Jaramillo, 2002, p. 7). 
A inicios del siglo XIX, América y, por supuesto, Nueva Granada, era un lugar poco explorado, por no decir desconocido, para los europeos; léase no español, puesto que la corona española se había encargado por tres siglos de mantener restringido el paso a sus dominios. Sabemos que los casos de La Condamine (1701-1774), quien visitó América en 1735, y de Humboldt, fueron excepciones. Entonces, ¿qué significó la independencia de América desde la perspectiva de viaje? El proceso de emancipación significó la apertura para la migración del personal europeo motivado por diversas intenciones. Es decir, con la independencia se facilitaba la visita al territorio, pues ya no era necesario solicitar un permiso para hacerlo; sencillamente, quien contaba con los recursos o con el respaldo de una institución podía desplazarse a tierras americanas, ya fuera para realizar investigaciones, contactos económicos, inventarios de la naturaleza, reconocimientos políticos 0 , simplemente, para hacer fortuna. Además, como nos dice Hans Joachim König (1994, p. 362), "La independencia parecía el comienzo de una era de nuevas relaciones entre América y Europa, en la cual América ofrecía sus diversas producciones en intercambio por los productos industriales de Europa".

Es necesario aclarar que la intención de viajar hacia América con algunos de estos objetivos, después del proceso de emancipación, no era una intención unilateral de las potencias europeas, también los criollos americanos contribuyeron y apoyaron las visitas de extranjeros y las migraciones de muchos europeos para poblar y mejorar la raza y la cultura. David Bushnell expresa claramente la posición que tomó el Gobierno de la Gran Colombia respecto a este tema de la inmigración:

La política de inmigración de la Gran Colombia se fundaba en la idea de que Colombia poseía una gran riqueza de recursos naturales que permanecía inexploradas y que una de las causas de ello era la escasez de población, la que a su vez se atribuía en gran parte a la hostilidad fanática de España en relación con la entrada de extranjeros a sus dominios. Sobre tales bases, el Congreso de Cúcuta expidió una ley de naturalización que se consideró como en extremo generosa, por la cual se invitaba a los extranjeros a venir "y formar una sola familia con los nacionales colombianos", que "ha sido privados hasta aquí de su fraternidad y de su industria, de sus artes y de sus conocimientos prácticos y de todos los beneficios" que una ola de inmigrante trae consigo... (Bushnell, 1985, p. 177).

Un ejemplo claro de este tipo de viajero fue el del francés Jean Baptiste Boussingault (1802-1887), quien tras rechazar una propuesta de viajar hacia oriente con un grado de honor en el ejército, se dirigió a América en 1820. Francisco Antonio Zea (1766-1822), comisionado por Bolívar (1783-1830) para establecer relaciones en el extranjero, contactó al viajero francés y le propuso un contrato por cuatro años, un pago de 7.000 francos y transporte en buque de guerra con el objetivo de realizar estudios en el campo de la geología y ayudar a la fundación de una escuela de ingenierías. Es así como el viaje de Boussingault, recomendado por Humboldt, se generó con la iniciativa del gobierno colombiano (Boussingault, 1994, p. 15). 
De modo que la oleada de viajeros de principios del siglo XIX fue, en gran parte, producto de los intereses comerciales que tenían las potencias europeas sobre las riquezas de América, pero al mismo tiempo fue un proceso aceptado e, incluso, buscado por la nueva élite Sudamericana. Si para los europeos, especialmente ingleses y franceses, América se convirtió en la posibilidad de obtener mercados y materias primas, para los americanos la relación económica y política con algunas potencias europeas se convirtió en la mejor opción de consolidar el proyecto independentista. Ahora bien, teniendo claro cuáles fueron los motivos que impulsaron la llegada a América de este grupo de viajeros, pasemos a explicar quiénes fueron los hombres que hicieron parte de esta avanzada.

\subsection{El perfil del viajero}

Para el caso de la Nueva Granada, el género que predominó en los viajeros de principios de siglo XIX fue el masculino. Hasta el momento, no se ha encontrado información sobre mujeres europeas, escritoras, que hubieran visitado el territorio ${ }^{2}$. Estos viajeros, como lo afirma Magnus Mörner (2000, p. 416), provenían es su mayoría de Inglaterra, Estados Unidos, Francia y Alemania.

Contaban con una edad que oscilaba entre los veinte y treinta años, aunque existieron excepciones, como el caso del diplomático inglés John Potter Hamilton (1777-1873), quien arribó a Colombia a los cuarenta y seis años, edad que prácticamente doblaba a la de sus colegas. Quizás la juventud con la que se afrontaban estos viajes se debía al rigor y la dificultad que suponía el traslado hacia los "inhóspitos" caminos de América. Los viajeros de la avanzada del capitalismo, según Magnus Mörner (Ibídem, pp. 416-147), pertenecieron por lo general a las clases medias urbanas europeas, donde habían tenido una vida relativamente confortable, y eso podría explicar lo extenuante que para ellos resultaba un viaje por tierras americanas. En su mayoría fueron religiosamente protestantes, hecho que puede explicar los fuertes ataques que hicieron a la iglesia católica y la crítica a sus tradicionales rituales.

Al ser viajeros-escritores, generalmente contaban con un nivel de escolaridad alto, puesto que la escritura de un relato no sólo consistía en hacer el recorrido. También, por una parte, se debían utilizar cuadernos de apuntes que sirvieran de base para, posteriormente, realizar la edición del relato de sus viajes. Y, por otra, se debía acometer la lectura de otros viajeros que sirvieran de guía y, a la vez,

\footnotetext{
${ }^{2}$ En otras partes de América Latina sí se encuentran casos de mujeres viajeras. Por ejemplo, Magnus Mörner plantea que de los 394 relatos de viajes registrados en México para el siglo XIX, 31 fueron escritos por mujeres. Asimismo, delimita un grupo de viajeras catalogadas dentro de las mejores exponentes del género. Ellas son: Fanny Calderón de la Barca, Maria Graham y Frederika Bremen. Ángela María Pérez incluiría en esta lista a Flora Tristán. De tal manera, tenemos que la presencia de mujeres europeas viajando por América es más común de lo que actualmente se piensa, de hecho esta última autora plantea que aunque existieron algunas mujeres que realizaron viajes durante diferentes épocas, sólo hasta el siglo XIX se empezaría a publicar sus relatos de viaje, bajo un fenómeno que la autora define como: "el boom de la literatura de viajes escrita por mujeres" (Pérez, 2002, p. 99).
} 
permitieran conocer lo que ya se había escrito, cuáles eran los lugares más visitados y cuáles los temas que podían ser desarrollados. La escritura de esta literatura de viajes se encontraba articulada a un mercado de consumo europeo que demandaba este tipo de género. Además, la descripción de un territorio suponía también que la persona que la realizara debía poseer puntos de comparación, lo que implicaba que el viajero autor debía tener un panorama cultural amplio. Leamos, en este sentido, lo que Jaramillo Uribe (2002, p. 25) dice del viajero sueco Gosselman: "A juzgar por sus frecuentes citas de autores latinos y por el hecho de poner su libro bajo el patrocinio intelectual del doctor Samuel Johnson (1709-1784), era hombre culto" (Jaramillo, 2002, p. 25).

Sumado al nivel de escolaridad, debían tener un conocimiento básico en el dibujo, pues sus textos fueron acompañados por grabados que, por lo general, se hacían con base en los bocetos que los viajeros les entregaban, en Europa, a artistas profesionales. De esta manera, dichas imágenes, o grabados, no siempre representan con fidelidad la realidad de los territorios visitados, pues entre el boceto y la imagen final que lograba plasmar un artista profesional, debieron haberse perdido muchos detalles. No obstante, existieron casos en que las expediciones, con un personal más amplio, incluían artistas profesionales con el objeto de pintar con mayor detalle el paisaje y las costumbres de la gente americana. O casos de viajeros pintores del siglo XIX, como François Roulin (1796-1874), Frederic Church (1826-1900) y Edward Walhouse Mark (1817-1895) para el caso colombiano.

Se desempeñaban en diferentes profesiones: comerciantes, empresarios, artistas, científicos, soldados o diplomáticos. No obstante, aunque sus profesiones, carácteres y nacionalidades fueron diferentes, lo cierto es que todos tenían un objetivo en común, el impulso de la conquista económica de América, pues así lo hicieran desde diferentes perspectivas todos estos viajeros pusieron bajo el ojo europeo las riquezas de América, que no se limitaban exclusivamente al campo de lo mineral, sino también al potencial vegetal, animal y humano.

Pero ¿bajo qué condiciones llegaron a América? Algunos fueron enviados directamente por sus países, ya fuera para el reconocimiento o la instauración de relaciones comerciales; otros remitidos por instituciones científicas como investigadores, lo que, por supuesto, generaba confianza al gobierno del país que visitaban, pues existía una institución seria que los respaldaba. También, por otro lado, hubo grupos de particulares, especialmente comerciantes, interesados en conocer la situación política, los recursos naturales y las posibilidades de explotación de una determinada región que patrocinaron viajes para observar las posibilidades de inversión y éxito que tenían en América Latina (Prieto, 1996). Un ejemplo de este tipo de viajero fue Luis Stiffler:

...contratado y traído a Colombia por Dujardin, un aventurero francés que se radicó en Cartagena, quien inició varias empresas mineras en Colombia que siempre quebraron. El viajó a Francia para conseguir inversionistas y técnicos para las nuevas minas, supuestamente muy ricas descubiertas por él 
en el alto Sinú. Stiffler, para el efecto, fue traído como mineralogista a Colombia, encargándosele los estudios, descripciones y análisis que demostrasen la factibilidad de una explotación minera de aluvión en grande, respaldada por enormes reservas. Las anotaciones de Stiffler sirvieron para que Dujardin convenciera a los inversionistas en Europa. Sin embargo, a pesar del optimismo en las descripciones del viajero, la empresa fracasó (Molina, 1985, p. 58).

Pero Gaspard Théodore Mollien llegó a América bajo otras condiciones. El viajero francés no hizo parte de una comisión científica, no fue enviado por su gobierno, ni fue contratado por inversionistas europeos. En verdad, para la élite política colombiana los intereses de viaje de Mollien nunca estuvieron claros y al no tener una institución oficial que lo respaldara, el francés dejo de ser un viajero para convertirse en un "sospechoso" que debía ser vigilado. Aunque su viaje nunca tuvo una relación directa con el gobierno francés, o por lo menos esto es lo que nos indican los archivos investigados, para el personal político de la época Mollien no dejó de ser más que un agente de la Restauración, sospecha que según ellos se comprobó cuando la primera edición de Viaje por la republica de Colombia en 1823 se divulgó en la capital.

\section{Un "espía" francés por las provincias de la Nueva Granada}

Gaspard- Théodore Mollien nació en París en 1796 en el seno de una familia noble, como vuelve a decirnos Jaime Jaramillo Uribe (2000, p. 25). Su padre, el conde Nicolás François-Mollien (1758-1850), hombre de estado y financista descendiente de una familia de comerciantes, estuvo completamente vinculado al gobierno napoleónico como Ministro del Tesoro. Tras la caída de Napoleón (17691821), el padre de Mollien se retiró de la administración de Francia, aunque no se desvinculó totalmente de los aspectos administrativos y financieros de la nación porque, en 1819, fue nombrado par de Francia y desde este puesto se convirtió en consejero de temas financieros y administrativos del Estado. Nicolás FrançoisMollien fue, sin duda, un hombre importante para la administración francesa; de hecho, Napoleón III (1808-1873), en pago a los servicios prestados a su tío, decidió premiarlo con el honor de tener un pabellón en el museo Louvre que llevara su apellido: Pabellón Mollien.

Hasta el momento no están claros cuáles fueron los estudios que desarrolló Gaspard Théodore Mollien y cuál fue su verdadera profesión, aunque se ha mencionado que después de su viaje a Colombia se dedicó a la diplomacia. Sin embargo, el contrato de Mollien con la editorial de Arthus Bertrand para la publicación de sus libros de viajes nos indica que por lo menos entre 1814, fecha en la que se dirigió al África, y 1825, fecha de la última edición corregida de Viaje por la República de Colombia en 1823, se dedicó exclusivamente a ser viajero. Su obra, además, en correspondencia, indica similar dedicación, pues destaca por encima de otros libros de viajes por su excelente elaboración que incluye descripciones, análisis y hasta revisión de fuente primarias del lugar visitado. 
Tras la caída de Napoleón partió a África a la edad de 18 años y fue su primera experiencia como explorador de un continente desconocido para él (Reyes, 1992). Se dirigió a Senegal con el cargo de Comisario de Marina en un barco francés llamado La Medusa que partió de Francia. Cerca de las costas del África esta fragata encalló y tras varios días de lucha por mantenerla a flote naufragó. Los sobrevivientes fueron pocos, Gaspard Théodore Mollien fue uno de ellos.

Tras superar el naufragio, Mollien llegó a costas africanas para realizar las respectivas observaciones que, tras una elaboración más detallada, se convertirían en aportes para la geografía del continente, principalmente, en lo que respecta a las fuentes de los ríos Senegal, Gambia y Nigeria. Algunos años después publicó su primer relato de viaje basado en esta experiencia que se tituló: Voyage dans l'intérieur de l'Afrique, aux sources du Senegal et de la Gambie ${ }^{3}$.

A pesar de su mala experiencia en el África, a los dos años de haber publicado este texto, en 1822, con 26 años, en un nuevo viaje, zarpó dentro de un buque de guerra hacia las Antillas. Este viaje de Mollien fue impulsado por su "curiosidad de aventurero", que despertó a partir del impacto que tuvieron las narraciones de independencia en el viejo continente. "Mollien quiere responderse ciertas inquietudes, saber cómo podrán organizarse estas nuevas sociedades, cómo podrán pasar desde una estructura rígidamente jerárquica y monárquica a una vida republicana" (Melo, 2007). Parece que el viajero francés no asimiló que un pueblo que viviera en territorios "deshabitados" pudiera apropiarse de principios políticos que no eran acordes a su cultura política.

Así, Gaspard Théodore Mollien llegó a Cartagena el 18 noviembre de 1822. Su viaje a la Nueva Granada, incluyendo el viaje de ida y vuelta a Europa, duró un año y seis meses. Partió de Francia en agosto de 1822 y regresó a ese mismo país el 13 de febrero de 1824. El recorrido que Mollien realiza por la Nueva Granada, lo inicia en la costa atlántica para posteriormente dirigirse al interior del país y de ahí a la costa pacífica.

En 1823 en la Nueva Granada, y en general en las ex colonias españolas, debido a la continua amenaza del proyecto de Restauración europea y sus implicaciones en el desarrollo de la independencia de América existió un ambiente de desconfianza hacia los franceses. Sin embargo, el gobierno colombiano sólo se preocupa realmente por Mollien cuando fragmentos de su texto completo comienzan a publicarse traducidos en La Gaceta de Colombia. Es el caso del extracto que apareció el 7 de agosto de 1825, donde se hizo una reproducción de su capítulo VIII que aparece comentado, posiblemente, por Francisco de Paula Santander (1792-1840), quien, por lo general, se encargaba personalmente de la edición de La Gaceta. Mollien hizo pública la miseria en la que se mantenían a los indígenas y los altos impuestos a los que se sometía al resto de la población. Pero lo que más molestó al personal político de la época fue el perfil crítico que

\footnotetext{
${ }^{3}$ Viaje al interior del África, a las fuentes del Senegal y de la Gambia que, lastimosamente, no tiene versión en lengua castellana.
} 
creó sobre Bolívar, inaceptable en un contexto donde el Libertador era la imagen de la independencia ante el resto del mundo.

Finalmente, salió de Colombia por Panamá el 18 de noviembre de 1824, embarcado en una goleta inglesa que se dirigió a Jamaica. Aunque este viaje por la Nueva Granada fue corto y Mollien tuviera prisa de abandonar Colombia -afán que nunca explicó- lo cierto es que su obra Viaje por la república de Colombia en 1823 logró generar un gran impactó en la élite política. Rápidamente la figura de este viajero francés dejó de ser la de un viajero "sospechoso" para convertirse en un "espía francés". Mollien, a mi parecer, fue una de las figuras más controvertidas de los viajeros que dejaron plasmadas sus huellas por Colombia en el siglo XIX. Murió en 1872 a sus 76 años de edad.

\subsection{Crítica al sistema de gobierno colombiano y al Libertador}

La Gaceta de Colombia anunció en los inicios del año 1823 que "el sr. Gaspar Moliens [sic], caballero de la lejion de honor [llegó] á Cartagena el 18 de noviembre último en la corbeta de guerra Tarn de S. M. cristianisima" (La Gaceta de Colombia, 1823, 2 de marzo, p. 1). Con esta noticia se hizo oficial la visita del viajero francés a la Gran Colombia. Sin embargo, parece que el arribo de Mollien no fue del agrado ni contó con la confianza de las autoridades nacionales, porque este viajero no traía ningún tipo de recomendación ni el respaldo de una institución científica y, menos, la del Estado francés. Para el gobierno colombiano no estaba muy claro cuál era el motivo del viaje de este extranjero y, aunque los puertos se habían abierto al mundo, esto no quería decir que las autoridades no estuvieran pendientes de quién llegaba a la nueva nación y con qué propósitos lo hacía. Por ello, al no tener un respaldo institucional, Gaspard Théodore Mollien se convirtió en un extranjero "sospechoso" para las autoridades colombianas.

Pero éste no fue el único motivo de las autoridades para sospechar del extranjero. Existe una razón más poderosa, que supera los límites nacionales y nos permite entender el por qué del trato que se le dio a Mollien en Colombia: la situación del mundo después de la independencia. Sabemos que las relaciones de los nuevos estados americanos con Francia no eran las mejores, puesto que Francia hacía parte del proyecto de la Restauración europea y, por tanto, estaba en contra de la instauración de gobiernos republicanos en cualquier parte del mundo. Además, los franceses no gozaban de muy buena reputación en el mundo hispánico desde la invasión de Napoleón a España. Después de ser por doce años los grandes aliados de España y de que sus ejércitos hubieran luchado juntos en Trafalgar y Dinamarca, debido a las ambiciones de Napoleón, los franceses se convirtieron en los "traidores invasores" en 1808. De modo que desde esta fecha "tener origen francés pasó de ser un mérito a sinónimo de sospecha, vigilancia, ataques o motivo de deposición, como fue el caso del virrey de Buenos Aires, Santiago Liniers (1753-1810), y el de otras autoridades civiles, militares o eclesiásticas" (Chust, 2007, p. 29). 
Por supuesto, el Virreinato de la Nueva Granada compartió esta "xenofobia antifrancesa" contra la nación que había traicionado al rey por el que aún se le profesaba lealtad en 1808. Y, al parecer, este reducto colonial de la desconfianza hacia los franceses estuvo presente durante los primeros años de vida republicana. Mollien no fue el único francés que despertó sospecha entre el personal político de la época. A propósito leamos el caso de M. Chasseriau, comisionado encargado de dirigir el pliego donde se explicaban los malos entendidos de un ataque francés contra Colombia, que nos sirve para entender la desconfianza profunda que había en torno a Francia y cómo durante este contexto el adjetivo de espía era utilizado para referirse a los ciudadanos franceses:

...no se confiaba mucho en la sinceridad de la Francia. Contribuyó a esto que el comisionado para conducir los pliego era M. Chasseriau, bien conocido en Venezuela y en la Nueva Granada. Creyese que un hombre tan astuto se había escogido de intento como un espía. Dondequiera se desconfió de él, y los papeles públicos denunciaron su visita como sospechosa. Si traía proyectos, nada pudo conseguir, porque se observaron cuidadosamente sus pasos (Restrepo, 1935, p. 144).

En 1823 hubo un fuerte rumor sobre una intervención de la Santa Alianza, específicamente una liga entre España y Francia contra los estados americanos. Se decía que después de lograda la reconquista, España dividiría el territorio americano o, por lo menos, sus posesiones con su aliado más cercano, en este caso Francia. No obstante, como lo afirma Manfred Kossok (1983, p. 139), parece que nunca existió un proyecto de tal magnitud y que la expansión de este rumor obedeció, más bien, a una estrategia de la política inglesa para lograr ventaja con respecto a otras potencias en la cuestión de crear relaciones de amistad y comercio con las nuevas naciones americanas. Estrategia que se desarrolló con éxito en un contexto de xenofobia antifrancesa. De este modo son más comprensibles los problemas que tuvo Mollien para hospedarse y el seguimiento al que fue sometido por parte del gobierno mientras recorrió los caminos de la Nueva Granada.

Podemos ejemplificar dicho seguimiento cuando, en Somondoco, a Mollien le solicitaron presentar su pasaporte ante la autoridad civil. Cuenta el viajero francés que se encontraba ya instalado cuando el alcalde, en compañía de varios "rufianes", llegó hasta su alojamiento para entregarle una carta. El funcionario se mantuvo atento a la cara de Mollien mientras él leía, sin embargo, dice el viajero francés: "...su contenido no era para inquietarme. Era del juez de Guateque, diciendo al alcalde que vigilase mis andanzas porque se creía que tenía intención de pasar de las regiones altas a los Llanos. Le encargaba expresamente que me pidiesen mi pasaporte" (Mollien, 1992, p. 111). Este acto de pedir pasaporte y de vigilar las andanzas no era un procedimiento normal de las autoridades con los viajeros, aunque como sostuvo La Gaceta de Colombia, en el mes de marzo, "...los especuladores tienen seguridad, y los viajeros, como Moliens [sic] no son incomodados ni detenidos, no obstante que su conducta inspire sospechas" (La Gaceta de Colombia, 1825, 27 de marzo, p. 3). Al considerársele sospechoso, 
Mollien fue víctima de los obstáculos que las autoridades civiles y eclesiásticas le impusieron.

Pese a los inconvenientes que sufrió en su recorrido por Colombia, Mollien recogió la información necesaria que le sirvió para crear su versión de esta nación en su título ya mencionado Viaje por la republica de Colombia en 1823. En 1825 ya existían comentarios sobre la obra, quizás por el afán del personal político colombiano de conocer lo que había escrito el viajero francés sobre la nueva nación. Como lo expresó Santander en carta dirigida a Bolívar, fechada el 21 de abril de 1825, "uno de los espías franceses ha publicado en París, no habla tan mal de Colombia como yo lo creía" (Santander, 1990, Tomo IV, p. 350). A lo que La Gaceta de Colombia agregó: "por fin hemos logrado leer la célebre obra del viajero francés Mollien" (La Gaceta de Colombia, 1825, 24 de abril, pp. 3-4). Contrario a lo que sucedió con otros viajeros, este texto fue muy leído en Colombia. Tal afirmación puede comprobarse a través de la correspondencia entre Santander y Bolívar, donde se encuentran varias menciones del texto; los comentarios de La Gaceta de Colombia; la publicación del capítulo VIII en el mismo periódico (La Gaceta de Colombia, 1825, 7 de agosto, p. 4) y el comentario de José Manuel Groot en Historia eclesiástica y civil de la Nueva Granada:

Otras cosas dio entretención a los bogotanos, y fue la lectura de los viajes de Mr. Mollien en Colombia. Algo dio de que reír a los hombres, y a las mujeres que rabiar; más no dejó de llevar sus buenas críticas. Pintó a las señoras recibiendo visitas de una manera bien miserable, en términos que dio lugar a que se dijese que, sin duda, en su mansión en Bogotá no ha visitado más que a las mujeres del pueblo [...] En política no dejó de decir buenas verdades Mr. Mollien, una de ellas que fue (profética), la que Colombia no duraría sino mientras viviese Bolívar (Groot, 1953, pp. 64-65).

Fueron precisamente sus comentarios en política, sumados a la sospecha que levantó su presencia en Colombia, lo que hizo de este libro un texto controversial por las críticas sin tapujos que su autor realizó a Simón Bolívar. Mollien se dio el "lujo" de realizar estas críticas o, simplemente, de expresar lo que pensaba por el hecho, hasta el momento irrefutable, de que fue un viajero independiente de las instituciones científicas y que no tuvo ningún tipo de relación con la élite política de la Nueva Granada, ni con ninguna institución estatal de su Francia natal ${ }^{4}$. Al parecer su única responsabilidad fue con la librería de Arthus Bretrand, encargada de la publicación de su Viaje por la República de Colombia en 1823 y la que, posiblemente, patrocinó su viaje a América.

El caso de Mollien es contrario al caso de John Potter Hamilton, viajero inglés y diplomático encargado del reconocimiento de la independencia de Colombia que, por su posición de diplomático, tuvo que matizar sus comentarios ante la opinión pública. Hamilton se transformó en un monarquista tolerante con el republicanismo, debido a los intereses comerciales que Inglaterra tenía sobre

\footnotetext{
${ }^{4}$ Mollien a diferencia de otros viajeros de principios del siglo XIX como John Potter Hamilton y Carl August Gosselman, no se entrevistó con Santander y, como todos, no conoció personalmente a Bolívar, porque el Libertador se encontraba en las batallas del sur.
} 
Colombia. Por ello, el viajero inglés observó la política colombiana con pocas críticas y creó una versión favorable sobre la transformación política que estaba sufriendo la nación en los inicios de su vida republicana. Para él, la independencia de la metrópoli permitiría que los principales protagonistas de la expansión europea, los ingleses, irrumpieran con su capital, su tecnología y sus productos en la nueva república. Aquí los principios políticos se dejaron al lado para dar prioridad al interés económico. La independencia, a pesar de simbolizar desorden, era la única forma efectiva de asegurar la intervención económica de Inglaterra en Sudamérica.

Gaspard Théodore Mollien sostuvo en su texto que la educación de Bolívar fue descuidada y que, más bien, su estadía en Europa lo convirtió en un aficionado: "la permanencia bastante larga en Europa despertó en él una gran afición por el estudio de las lenguas y de la historia" (Mollien, 1992, p. 177). Afirmación que provocó en el gobierno colombiano y hasta en el mismo Bolívar un fuerte rechazo. De esta manera, La Gaceta de Colombia dedicó una sección a refutar las ideas de Mollien en su afán de limpiar la imagen de Bolívar. Para ello, el periódico se introdujo en un juego de refutaciones, donde el objetivo era desacreditar la veracidad de Mollien como escritor. Después de publicar el capítulo VIII del texto de Mollien, donde aparece el comentario sobre la educación de Bolívar, La Gaceta responde de la siguiente manera:

Hemos querido conservar las ideas y opinión del viajero y ser fieles en la publicación del concepto que ha hecho del LIBERTADOR presidente; porque cuando un hombre llegará a una altura eminente de reputación por hechos repetidos, y muy notorios, ninguna mancha ni demerito puede recaer sobre ella por las ideas mesquinas [sic] de un escritor obscuro, que más que viajero filósofo, es un mero peregrino (La Gaceta de Colombia, 1825, 7 de agosto, p. $4)$.

Cuando se publicó esta noticia, Bolívar ya sabía lo que el viajero francés había escrito sobre su educación y, por tanto, tenía clara cuál era la visión que Mollien había construido en torno a él y al vicepresidente Francisco de Paula Santander. El Libertador, en carta dirigida al vicepresidente el 20 de mayo de 1825, le comenta en forma aclaratoria que:

[...] He visto con infinito gusto lo que dice de usted monsieur Mollien. A la verdad, la alabanza de un godo servil, embustero, con respecto a un patriota que manda una república, no deja de ser muy lisonjero. El dice que usted tiene talentos rarísimos de encontrarse. Esto es de un europeo que presume de sabio: que le pagan para que desacredite a los nuevos estados. Mucho me he alegrado del sufragio que usted ha merecido de este caballero. Lo que dice de mí es vago, falso e injusto. Vago, porque no asigna mi capacidad; falso, porque me atribuye un desprendimiento que no tengo; e injusto, porque no es cierto que mi educación fue muy descuidada, puesto que mi madre y mis tutores hicieron cuanto era posible por que yo aprendiese, me buscaron maestros de primer orden en su país (Bolívar, 1990, Tomo IV, pp. 378-379). 
Estas dos citas nos muestran el concepto que los políticos colombianos, especialmente Bolívar y Santander, los dos hombres más importantes de Colombia, tenían sobre Mollien, que podría resumirse con las siguientes denominaciones: "espía", "peregrino", "godo servil", "embustero", "europeo que presume de sabio", y lo que es peor, que le "pagan para que desacredite a los nuevos estados". Es necesario señalar que las críticas procedentes del mundo político a los libros de viajes, sólo se dan cuando los contenidos del texto son de un interés nacional ${ }^{5}$. $Y$ en este sentido, cómo no va a ser importante lo que dice un francés, de quien se sospechaba que era enviado por su gobierno, cuando estamos hablando de un contexto en donde en cualquier momento puede llegar un nuevo ataque contra las naciones y cuando el reconocimiento de la independencia y los tratados de amistad y comercio con otras naciones eran una de las preocupaciones centrales.

Mollien continuó hablando de lo que fue el principal campo de acción de Bolívar, la guerra. Llegó al extremo de expresar que Bolívar no era un buen estratega militar: "sus métodos de hacer la guerra, sus largas marchas para alcanzar al enemigo, la rapidez con que recorre distancias inmensas para darle alcance, le presentan más bien como un guerrillero atrevido que como un general hábil en la disposición de las masas de hombres" (Mollien, 1992, p. 177). Contrario a lo que uno podría pensar, pues este es el campo de acción más importante de Bolívar, no hubo una sola refutación a este comentario, que produjo un silencio sepulcral, tanto en la correspondencia entre Santander y Bolívar como en La Gaceta de Colombia.

Otras dos grandes críticas al Libertador que encontramos en su libro de viajes son las referentes a su aspiración de convertirse en dictador y a su régimen centralista. Mollien sintió una profunda desconfianza por la forma en que Bolívar ejercía la política; por las ambiciones que, según el viajero, tenía el Libertador de dejar de ser un presidente electo bajo la democracia para convertirse en dictador. La historia, parece ser, se encargó de demostrar que el viajero francés estaba en lo cierto. Los argumentos que exponía Mollien para sostener que detrás de las buenas intenciones de Bolívar se encontraba su anhelo por la dictadura, eran su control sobre el ejército y el título de Libertador que se había hecho otorgar:

[...] El título de Libertador [...] nuevo en las lenguas modernas, es sinónimo de los de dictador o protector. Hasta ahora no hay motivo para quejarse de su despotismo, y si no fuese porque empieza a desterrar a los descontentos y a confiscar sus bienes, no habría que reprocharle más que el haber usado algunas veces de represalias durante la guerra (Mollien, 1992, p. 180).

Estuvo seguro, como afirma desde la introducción del texto, de que los colombianos no entendían muy bien algunos conceptos básicos de republicanismo. Menos, todavía, el ejército, porque "su ignorancia comprendía mal esos conceptos de independencia y libertad, pero eran sensibles a las

\footnotetext{
${ }^{5}$ De otros autores de libros de viajes de principios del siglo XIX como, por ejemplo, Carl August Gosselman, Charles Stuart Cochrane y John Milton Niles no se encuentra ningún tipo de comentario en la prensa o en los libros de la época.
} 
distinciones, y Bolívar sabía crearlas y distribuirlas" (Mollien, 1992, p. 175). Mollien creía que el ejército colombiano combatía más por fidelidad y admiración hacia Bolívar que por su convicción en la independencia y las instituciones con que se había dotado a la nueva nación. "El ejército es, el cuerpo y alma, del gobierno actual, menos tal vez por entusiasmo por las instituciones que éste representa que por adhesión a los hombres que las establecieron; si Bolívar -afirmaba Mollienpidiera a sus soldados la corona, estos le llevarían al triunfo" (Mollien, 1992, p. 238).

La crítica del viajero a su régimen centralista proviene del convencimiento de Mollien de que éste era un mal sistema de gobierno para la joven nación, puesto que la centralización del poder en manos de Bolívar era la forma más rápida de que el Libertador llegara a convertirse en dictador. Pensó que el congreso que votó en Cúcuta por la instauración del gobierno centralista estaba manipulado o, si se quiere, guiado por la opinión del Libertador. Tal decisión se debió a que "todo[s] [en este caso los representantes] cedía[n] ante la voluntad del dictador Bolívar" (Mollien, 1992, p. 175). Recordemos que desde el discurso de Angostura de 1819 hasta el congreso de 1821, Simón Bolívar fue el mayor defensor del centralismo. De esta manera se manifestaba Mollien acerca del régimen centralista:

Si las formas del gobierno colombiano tienen cierta analogía con las de la República de los Estados Unidos, su principio constitucional dista mucho de ser el mismo. En Colombia el poder está centralizado en las manos del presidente; en estas condiciones, ¿cómo podrían los quince senadores y los cuarenta y cinco diputados que integran el Congreso, contrabalancear por sí solos la autoridad de un jefe emprendedor, victorioso, idolatrado por quince mil soldados y dueño del tesoro del Estado? En Norte América la administración de las provincias no está tampoco confiada a intendentes militares, satélites de su general: allí cada provincia tiene sus estados, sus leyes y sus privilegios; la federación se mantiene en un equilibrio perfecto, que la Presidencia no puede romper, a menos que una facción no llevase a ella un Sila. La democracia, cuando existe sólo en las altas clases sociales, con su sede en una ciudad privilegiada donde impera gracias a un jefe militar, no es más que el primer paso hacia la tiranía [...] Sólo el sistema federal puede preservar del despotismo a las grandes repúblicas. (Mollien, 1992, p. 178).

Mollien insistió en que el sistema federal era la única forma de gobierno que podría salvar a Colombia de un despotismo. Por ello, al regirse por un sistema centralista en donde el poder estaba concentrado en un jefe militar que impedía que el resto del personal político tuviera una participación activa en las decisiones más importantes de la nación, la Gran Colombia estaba, según el francés, destinada a la tiranía.

Su crítica al modelo de régimen centralista, que desde su visión había sido obra de Simón Bolívar, lo impulsó a apoyar cualquier iniciativa federalista. En este sentido compartió lo que algunos políticos de la época, entre ellos Francisco de 
Paula Santander, defendieron. Esto ayuda a entender por qué mientras hubo una excesiva antipatía por Simón Bolívar, el viajero tuvo palabras más elogiosas por Santander: "su entereza, por todos reconocida, le valió la Vicepresidencia. En este nuevo puesto ha desplegado un talento y un mérito poco frecuentes" (Mollien, 1992, p. 180). De ese modo terminó simpatizando con esta facción política de la época de la Gran Colombia.

La visión de la historia política de la Gran Colombia, de la que la Nueva Granada hacía parte, ofrecida por Gaspard Théodore Mollien, sirvió de sustento a los relatos antibolivarianos de historiadores colombianos del siglo XIX; el mito del Bolívar dictador tuvo su repercusión en las obras de José María Samper, Apuntamientos para la historia de la Nueva Granada (1984, pp. 60-64). , y José Manuel Groot (1953, pp. 64-65), que consideró "profético" el examen político del viajero francés.

Estuvo convencido, por otro lado, de que la unión de Colombia no duraría mucho tiempo por las evidentes diferencias culturales, sociales, económicas y grandes intereses particulares que existían en cada una de las diferentes regiones. En 1823, Mollien advirtió que estaba "a punto de producirse una escisión que amenazaba con separar a cada provincia" (Mollien, 1992, p. 196). El viajero sabía que la Gran Colombia fracasaría por la falta de intereses sólidos para mantener la unión después de que la guerra terminara. Estaba seguro de que en el momento en que Bolívar faltara Colombia, ésta se derrumbaría, pues el Libertador era el eje sobre el cual gravitada la nueva nación.

Cuando el personal político de la época tuvo clara la posición del viajero sobre las transformaciones que estaban sufriendo las nuevas repúblicas de América, pensaron dar una respuesta a lo que había escrito con respecto a Colombia. Por ello, O' Leary (1801-1854) le aconsejó a Santander: "que sería conveniente la refutación de la obra de Mollien" (Santander, 1990, Tomo IV, p. 6), quizás como una forma de combatir lo escrito por el "espía" francés, ya que muchos de estos libros de viajes se convirtieron en la imagen de Colombia ante el mundo o, por lo menos, lo que los hombres distantes del continente conocían sobre la nueva nación.

Sin embargo, La Revista Enciclopédica de Francia se adelantó a los presupuestos de la élite política colombiana y publicó una crítica a la obra de Mollien. La revista consideró el escrito como "parcial", "defectuoso" y con algunas "inexactitudes" y, respecto a su visión política sobre la Gran Colombia, afirmó que "Mr. Mollien afecta siempre presentar el estado de la República de Colombia bajo un punto de vista poco favorable: él sospecha de la moderación de BOLIVAR, y de los sentimientos republicanos del pueblo" (La Gaceta de Colombia, 1826, 6 de agosto, p. 4). Pese a su mirada crítica con respecto al libro, la revista aceptó, para no caer en la misma "parcialidad" de Gaspard Théodore Mollien, que Viaje por la república de Colombia en 1823 contenía noticias apreciables con algunos actos de justicias del autor. 


\section{Conclusiones}

Las precedentes observaciones nos han permitido demostrar que los viajeros europeos que arribaron al "Nuevo Mundo" a principios del siglo XIX fueron los viajeros de la avanzada del capitalismo. Hombres entre los treinta y los cincuenta años, de diversas profesiones, pertenecientes a las clases medias europeas, protestantes en su mayoría y con un alto nivel de escolaridad que llegaron a América con el objetivo de observar las posibilidades de inversión de capital, extracción de materias primas y definición de mercados para los productos europeos.

La llegada de este grupo de viajeros a América estuvo estrechamente relacionada con la expansión comercial de las potencias europeas, el progreso de los medios de transporte y la independencia de las ex colonias españolas que les permitió desplazarse a los puertos de Sudamérica sin mayores obstáculos. Así, las potencias europeas tuvieron que esperar a que en 1810 las barreras del colonialismo se desplomaran para pasearse por los territorios americanos. Los viajeros europeos se enfrentaron a un continente, prácticamente, nuevo e inexplorado por sus naciones. Para ellos, todo lo que observaron era desconocido, puesto que la corona española había mantenido a sus países de origen Inglaterra, Francia, Suecia, entre otros- alejados de las colonias americanas.

Gaspard Théodore Mollien perteneció a este grupo de viajeros de la avanzada del capitalismo y, aunque dedicó buena parte de su libro de viajes al balance de los recursos naturales, en Viaje por la República de Colombia en 1823 también hubo espacio para realizar un examen político sobre la nación. La visión que Mollien creó sobre la política de la Nueva Granda estuvo estrechamente relacionada con su posición como agente de la Restauración europea. Por lo tanto, Mollien fue, ante todo, un noble antirrepublicano que, determinado por la ideas de la Restauración, realizó sus observaciones e interpretaciones sobre la política colombiana. De ahí las fuertes críticas que aparecieron plasmadas en su libro. Para él, el único gobierno legítimo era el de las monarquías y, por ello, su desconfianza al republicanismo, que le parecía un sistema político incomprensible para hombres que aún se encontraban en un estado de desarrollo inferior al europeo.

Para la élite política de Colombia, Mollien, más que un viajero, fue un "espía" enviado por los franceses para desacreditar las nuevas naciones que surgían en América. Esta desconfianza hacia el viajero francés estuvo determinada por la mala reputación que tenía Francia como aliada y por la tensión que existía, en 1823, entre Colombia y Francia debido a la sospecha de una nueva reconquista franco-española apoyada por la Santa Alianza.

A nuestro parecer, Viaje por la República de Colombia en 1823, a pesar de estar reproduciendo un discurso que toca a todos los viajeros de la avanzada del capitalismo, en su esencia es único, pues Mollien, en un contexto de tratados comerciales y amistad, no cayó en el círculo vicioso de la hipocresía y, aunque 
sabía que su país y la misma Colombia necesitaban acercarse comercialmente, no dudó en realizar críticas al sistema político. Así, esta obra destacó las riquezas naturales de Colombia a la vez que mostraba las falencias de su sistema de gobierno y de su político insignia: Bolívar.

\section{Fuentes Documentales}

\section{Literatura de viajes}

Boussingault, Jean Baptiste. (1994). Memorias. Bogotá: Comisión Preparatoria para el V Centenario de Descubrimiento de América, Instituto Colombiano de Cultura, Banco de la República.

Gosselman, Carl August. (1981). Viaje por Colombia 1825 y1826. Bogotá: Publicaciones del Banco de la República.

Mollien, Gaspard Théodore. (1824). Voyage dans la République de Colombia 1823. París: Arthus Bertrand.

(1944). Viaje por la República de Colombia en 1823. Bogotá: Biblioteca Popular de Cultura Colombiana.

-------. (1992). Viaje por la república de Colombia en 1823. Bogotá: Comisión Preparatoria para el V Centenario de Descubrimiento de América, Instituto Colombiano de Cultura, Banco de la República.

\section{Prensa}

La Gaceta de Colombia. (1823, 2 de marzo). Bogotá. № 72.

La Gaceta de Colombia. (1825, 27 de marzo). Bogotá. № 180.

La Gaceta de Colombia. (1825, 24 de abril). Bogotá. № 184.

La Gaceta de Colombia. (1825, 7 de agosto). Bogotá. № 199.

\section{Correspondencia}

Carta de Bolívar a Santander, Arequipa, 20 de mayo de 1825. (1990). En Cartas de Santander-Bolívar 1826-1830, (tomo IV). Bogotá: Biblioteca Presidencial de la República.

Carta de Santander a Bolívar, Bogotá, 21 de abril de 1825. (1990). En Cartas de Santander-Bolívar 1826-1830, (Tomo IV). Bogotá: Biblioteca Presidencial de la República.

Carta Santander a Bolívar, Bogotá, 19 de julio de 1826. (1990). En Cartas de Santander-Bolívar 1826-1830, (Tomo IV). Bogotá: Biblioteca Presidencial de la República. 


\section{Bibliografía}

Bushnell, D. (1985). El Régimen de Santander en la Gran Colombia. Bogotá: El Áncora Editores.

Chust, M.. (2007). Un bienio trascendental: 1808-1810. En: 1808 la eclosión juntera en el mundo hispánico. México: Fondo de Cultura Económica.

Ette, O. (1999). "Un culpable inocente. ¿Es correcto ver en el "conquistador científico" un precursor de la conquista y penetración económica de la América Latina?" En: Humboldt. №126. Federal Republic of Germany: Inter Nationes.

Groot, J. M. (1953). Historia eclesiástica y civil de la Nueva Granada. Bogotá: Editorial A. B.C.

Jaramillo Uribe, J. (2002). "La visión de los otros. Colombia vista por observadores extranjeros en el siglo XIX”. En: Historia Crítica. № 24. Bogotá: Universidad de los Andes.

König, H. J. (1994). EN EL CAMINO HACIA LA NACIÓN. Nacionalismo en el proceso de formación del Estado y de la Nación de la Nueva Granada 1750 a 1856. Bogotá: Banco de la República.

Kossok, M. (1983). Historia de la Santa Alianza y la emancipación de América Latina. México: Editorial Cartago.

Melo, J. O. La mirada de los franceses: Colombia en los libros de viaje durante el siglo XIX. [Online]. Disponible en: http://www.lablaa.org/blaavirtual/sociologia Imelo/franceses.htm [El documento no tiene fecha de creación. Se indica aquí y en las citas del texto la fecha de consulta: lunes, 12 de febrero de 2007].

Molina, L. F. (1985). "Los relatos de los viajeros del siglo XIX. El caso de los viajeros extranjeros en Antioquia". En: Universidad Nacional de Colombia. № 020. Bogotá.

Mörner, M. (2000). Viajeros e inmigrantes europeos como observadores e intérpretes de la realidad latinoamericana del siglo XIX. Stockholm: Institute of Latin Americana Estudies.

Pérez Mejía, Á. (2002). La geografía de los tiempos difíciles: escritura de viajes a Sur América durante los procesos de independencia 1780-1849. Medellín: Editorial Universidad de Antioquia.

Posada, E. (1939). "El viaje de Mollien a Colombia". En: Revista Geográfica de Colombia. № 9. Bogotá: Instituto Geográfico Militar.

Pratt, M. L. (1997). Los ojos imperiales, literatura de viajes y transculturación. Buenos Aires: Universidad Nacional de Quilmes. 
Prieto, A. (1996). Los viajeros ingleses y la emergencia de la literatura argentina: 1820-1850. Buenos Aires: Editorial Suramericana.

Restrepo Saenz, E. (1935). "Impresiones de viaje del Primer Ministros británico en Colombia". En: Conferencias dictadas en la Academia Colombiana de Historia de Bogotá con motivos de los festejos patrios. Bogotá: Imprenta de La Luz.

Samper, J. M. (1984). Apuntamiento para la historia de la Nueva Granada. Bogotá: Editorial Incunables.

Sanhueza Cerda, C. (2006). Chilenos en Alemania y alemanes en Chile. Viaje y nación en el siglo XIX. Chile, Santiago: Ediciones Lom,

Fecha de recepción: 28 de mayo de 2009

Fecha de aprobación: 21 de septiembre de 2009 